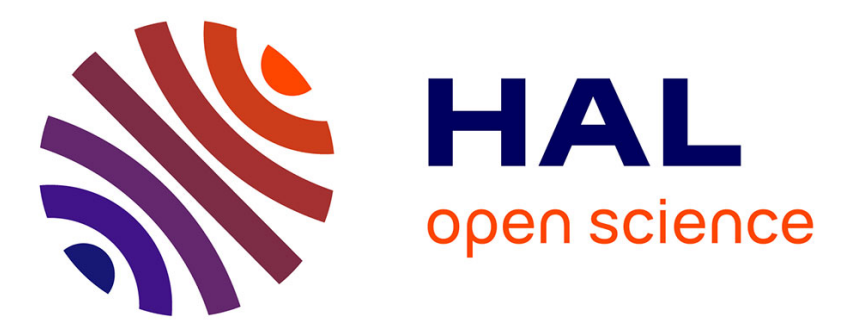

\title{
The pluripotency rheostat Nanog functions as a dimer
} Nicholas P Mullin, Adam Yates, Arthur J Rowe, Bianca Nijmeijer, Douglas Colby, Paul N Barlow, Malcolm D Walkinshaw, Ian Chambers

\section{To cite this version:}

Nicholas P Mullin, Adam Yates, Arthur J Rowe, Bianca Nijmeijer, Douglas Colby, et al.. The pluripotency rheostat Nanog functions as a dimer. Biochemical Journal, 2008, 411 (2), pp.227-231. 10.1042/BJ20080134 . hal-00478956

\section{HAL Id: hal-00478956 https://hal.science/hal-00478956}

Submitted on 30 Apr 2010

HAL is a multi-disciplinary open access archive for the deposit and dissemination of scientific research documents, whether they are published or not. The documents may come from teaching and research institutions in France or abroad, or from public or private research centers.
L'archive ouverte pluridisciplinaire HAL, est destinée au dépôt et à la diffusion de documents scientifiques de niveau recherche, publiés ou non, émanant des établissements d'enseignement et de recherche français ou étrangers, des laboratoires publics ou privés. 


\title{
The pluripotency rheostat Nanog functions as a dimer
}

\author{
Nicholas P. MULLIN*, Adam YATES*, Arthur J. ROWE $\uparrow$, Bianca NIJMEIJER*, Douglas \\ COLBY*, Paul N. BARLOW \\ * MRC Centre Development in Stem Cell Biology, Institute for Stem Cell Research, School of \\ Biological Sciences, University of Edinburgh, King's Buildings, West Mains Rd., Edinburgh EH9 \\ 3JQ, UK
}

$\uparrow$ NCMH Business Centre, School of Biosciences, University of Nottingham, Sutton Bonington, Leicestershire, LE12 5RD, UK

\$ Schools of Chemistry and Biological Sciences, University of Edinburgh, West Mains Rd., Edinburgh EH9 3JJ, UK

$\S$ The Centre for Translational and Chemical Biology, School of Biological Sciences, University of Edinburgh, King's Buildings, Mayfield Rd., Edinburgh EH9 3JR, UK

\section{Running header: Nanog functions as a dimer}

|| To whom correspondence should be addressed (ichambers@ed.ac.uk)

$$
\text { Word count }=3,540
$$

\section{FOOTNOTES}

Abbreviations used are : AUC - analytical ultracentrifugation, ES cells - embryonic stem cells, LIF leukaemia inhibitory factor, CD1 - C-terminal domain 1, CD2 - C-terminal domain 2, HD homeodomain, ND - N-terminal domain, WR - tryptophan repeat, MBP - maltose binding protein, rNanog - recombinant Nanog, SEC - size exclusion chromatography, EMSA - electrophoretic mobility shift assay, SV - sedimentation velocity, SE - sedimentation equilibrium 


\section{SYNOPSIS}

The defining activity of the homeodomain protein Nanog is the ability to confer cytokine-independent self-renewal upon embryonic stem (ES) cells in which it is overexpressed. However, the biochemical basis by which Nanog achieves this function remains unknown. Here we show that Nanog dimerises through a functionally critical domain. Co-immunoprecipitation of Nanog molecules tagged with distinct epitopes demonstrates that Nanog self-associates through a region in which every fifth residue is tryptophan. In vitro binding experiments establish that this region participates directly in selfassociation. Moreover, analytical ultracentrifugation indicates that, in solution, Nanog is in equilibrium between monomeric and dimeric forms with a $\mathrm{K}_{d}$ of $3 \mu \mathrm{M}$. The functional importance of Nanog dimerisation is established by ES cell colony-forming assays in which deletion of the tryptophan repeat region eliminates the capacity of Nanog to direct LIF-independent self-renewal.

Key words: ES cell, self-renewal, homeodomain, homodimer, cytokine, commitment 


\section{INTRODUCTION}

Embryonic stem (ES) cells present an interesting paradox because they can both self-renew and differentiate into derivative cells of all three primary germ layers [1]. Indeed, the simultaneous possession of these properties defines ES cells and promises to make them useful for regenerative therapies. It is therefore important that the mechanisms directing optimal ES cell self-renewal are elucidated fully to allow rapid expansion of pluripotent cells.

Nanog was identified on the basis of its functional capacity, when overexpressed, to enhance ES cell self-renewal efficiency to the point of cytokine-independence [2, 3]. Conversely, deletion of Nanog from ES cells co-cultured with fibroblasts produced Nanog-null colonies that expanded into primitive endodermal cell lines [3]. Subsequent studies also found an increase in the propensity of ES cells to differentiate upon knock-down of Nanog [4-6]. However, our recent studies show that loss of Nanog expression is not inextricably linked to commitment to differentiation and that cells lacking detectable Nanog expression can revert their Nanog expression status [7]. Moreover, Nanog ${ }^{-/}$ES cells can be established and retain pluripotency [7]. Nanog $^{-/}$ES cells do have an increased propensity to differentiate and the stepwise reduction in the number of wholly undifferentiated colonies formed by Nanog ${ }^{+/+}, \mathrm{Nanog}^{+/-}$and Nanog ${ }^{-/}$ES cells, underscores the quantitative effect of Nanog upon selfrenewal efficiency [7]. Altogether, these data suggest that rather than being essential for self-renewal, Nanog regulates ES cell self-renewal efficiency by acting as a rheostat to confer a variable resistance to differentiation. However, the biochemical basis of these observations remains unclear.

The 305 residue Nanog protein contains a typically folded homeodomain (HD; residues 96155) [8]. Outwith the HD, the most notable sequence encompasses residues 198-243 in which every fifth residue is tryptophan (the tryptophan repeat; WR) $[9,10]$. Here we report a recombinant expression system that has allowed us to begin biophysical characterization of Nanog. Together with ES cell studies this approach identified WR as a functionally critical dimerisation domain.

\section{EXPERIMENTAL \\ DNA constructions}

Full-length Nanog and $\operatorname{Nanog}_{1-160}$ were expressed in pET15b. To produce maltose binding protein (MBP) the open reading frame (ORF) in pMALC2E (NEB) was truncated by mutagenesis immediately after the enterokinase cleavage site. To produce MBP-WR codons $\mathrm{S}_{192}-\mathrm{G}_{252}$ of Nanog were amplified and cloned into pMALC2E. Trimerised HA or Flag tags followed by a glycine spacer were added at the 5' end of ORFs immediately upstream of the initiator methionine codon and cloned into the episomal vector pPyCAGIP [2]. Truncation constructs were prepared by introducing stop codons following $\mathrm{W}_{159}(\mathrm{Nanog} \Delta \mathrm{C})$ or $\mathrm{L}_{256}(\mathrm{Nanog} \Delta \mathrm{C} 49)$. In Nanog-C, codons 1-155 were deleted from (HA) $)_{3}$ Nanog. In Nanog $\Delta \mathrm{WR}$, residues $\mathrm{L}_{188}-\mathrm{L}_{248}$ were replaced with a linker encoding AlaSer. All constructs were checked by sequencing and details are available on request.

\section{Expression and purification}

Full-length Nanog and $\operatorname{Nanog}_{1-160}$ were expressed in E. coli BL21 (DE3) plysS and MBP constructs in E. coli BL21. Bacteria were grown to O.D. $=\sim 0.6$ before induction (1 mM isopropyl $\beta$ D-1-thiogalactopyranoside, $30^{\circ} \mathrm{C}, 3 \mathrm{~h}$ ). $\operatorname{Nanog}_{1-160}$ was purified from soluble lysate using a 1-ml Histrap column (GE Healthcare). Full-length Nanog was solubilized from inclusion bodies $(25 \mathrm{mM}$ Hepes $\mathrm{pH} 7.4,300 \mathrm{mM} \mathrm{NaCl}, 8 \mathrm{M}$ urea, $10 \mathrm{mM} \beta$-mercaptoethanol) and loaded onto a nickelsepharose column equilibrated in the same buffer. Protein was refolded by removal of urea over 40 column volumes and eluted with $250 \mathrm{mM}$ imidazole. For further manipulation, NP-40 was added (to $0.025 \% \mathrm{v} / \mathrm{v}$ ). Detergent-free rNanog was prepared by removing NP-40 with Extractigel (Pierce). MBP proteins were purified from soluble lysates on amylose resin (MBP) or by a combination of nickel and amylose resin (MBP-WR).

\section{Analytical centrifugation}

All studies were performed $\left(20+/-0.5^{\circ} \mathrm{C}\right)$ in a Beckman XL-A analytical ultracentrifuge (detailed protocols are in Supplementary material).

\section{Cell transfections}

For functional assessment of mutant Nanog molecules, E14/T cells were transfected and processed as described [11]. On day 12, cells were stained using an alkaline phosphatase kit (86R, Sigma). Transfection and processing for co-immunoprecipitation is described in Supplementary material. 


\section{Binding of recombinant Nanog to ES cell lysates}

ES cells were transfected and lysates prepared at $24 \mathrm{~h}$ post-transfection as described above. 5 $\mu \mathrm{g}$ rNanog was then added to each lysate and incubated $\left(4{ }^{\circ} \mathrm{C}\right)$ overnight. Finally, $5 \mu \mathrm{g} \alpha$-FLAG M2 antibody (Sigma) or $\alpha$-Nanog [12] was added and incubated (3h). Immune complexes were collected and analyzed as described in Supplementary material.

\section{Binding of recombinant Nanog to MBP-fusion}

MBP and MBP-WR were immobilized on a $0.2-\mathrm{ml}$ amylose column pre-equilibrated in 25 $\mathrm{mM}$ Hepes $\mathrm{pH} 7.4,300 \mathrm{mM} \mathrm{NaCl}, 0.025 \% \mathrm{NP}-40$. Then $5 \mu \mathrm{g}$ rNanog was loaded onto the column (same buffer) and incubated $\left(4^{\circ} \mathrm{C}, 1 \mathrm{~h}\right)$ before washing with 50 column volumes of the same buffer. Protein fractions eluted with $10 \mathrm{mM}$ maltose were separated by SDS-PAGE and immunoblotted using $\alpha$-Nanog antibody [12].

\section{RESULTS \\ Expression of full length Nanog}

Attempts to express full-length Nanog in E. coli resulted in the accumulation of large amounts of insoluble material, with little soluble Nanog, under a wide range of conditions (variations in cell type, temperature, IPTG concentration, time of induction, etc.). An on-column refolding protocol was therefore developed (see Experimental). Soluble protein eluting from this column (recombinant Nanog, $\mathrm{rNanog}$ ) (yield $=100-300 \mu \mathrm{g} /$ litre of culture) was sufficiently pure for further studies (Fig. 1B). Under approximately physiological conditions ( $\mathrm{pH} 7.4,200-300 \mathrm{mM} \mathrm{NaCl}$ ) rNanog was difficult to handle with losses accompanying further manipulation e.g. dialysis, buffer exchange etc. Similar observations were made with the small amounts of soluble Nanog obtained both from E. coli and from expression in insect cells, indicating that this behaviour is a feature of the protein rather than the production protocol. A low concentration of detergent $(0.025 \% \mathrm{NP}-40(\mathrm{v} / \mathrm{v}))$ stabilized rNanog.

\section{Recombinant Nanog has biological activity}

To investigate whether rNanog adopts a native conformation, binding to known Nanog targets was assessed. A target site identified by SELEX [3] was used to examine DNA binding of rNanog. A mobility shift was observed that could be specifically competed with unlabeled oligonucleotide (Supplementary Figure 1A). We next investigated binding of rNanog to known protein partners, Sall4 and SMAD1 [10, 13]. Addition of rNanog to lysate from ES cells expressing (Flag) ${ }_{3}$ SMAD1-MH2 allowed co-immunoprecipitation of SMAD1-MH2 and Nanog (Supplementary Figure 1B). Similarly, when rNanog was incubated with lysate from ES cells expressing (Flag) ${ }_{3}$ Sall4, Nanog and Sall4 could be co-immunoprecipitated (Supplementary Figure 1C). Together these data indicate that rNanog has a native structure in terms of its ability to interact with Sall4, SMAD1 and DNA.

\section{Dimeric nature of Nanog}

Analytical ultracentrifugation (AUC) was used to further characterize rNanog. Sedimentation velocity measurements indicated that $\mathrm{rNanog}$ is predominantly a single oligomeric species $(>90 \%)$ with a sedimentation coefficient of $4.5 \mathrm{~S}(2.25 \mathrm{~S}$ in the presence of NP-40). This eliminates any concern that rNanog may contain a significant proportion of non-specifically aggregated material. A value of $4.5 \mathrm{~S}$ corresponds to a molecular weight of approximately $74 \mathrm{kDa}$, consistent with a dimeric form for Nanog.

By sedimentation equilibrium, excellent fits were obtained (Fig. 1C-E) giving estimates of $\mathrm{K}_{d}$ for Nanog dimerisation of $12 \mu \mathrm{M}$ (with NP-40 in 'ordinary' buffer), $60 \mu \mathrm{M}$ (with NP-40 in $\mathrm{O}^{18}$-water buffer) and 3.2 $\mu \mathrm{M}$ (without NP-40). These results suggest that under all conditions studied Nanog will be in equilibrium between dimer and monomer, with the dimer predominating.

\section{Hydrodynamic behaviour of Nanog}

To further characterize rNanog, size exclusion chromatography (SEC) was performed. Rather than migrating in the expected position for a dimer, rNanog is present in early eluting fractions (Fig.1F). Interestingly, and consistent with previous observations [14] we found that Nanog is present in ES cell lysate fractions corresponding to apparent molecular weights ranging from approximately two megadaltons to below that expected for monomeric Nanog (35-40 kDa, Fig. 1F). This behaviour had previously been considered to indicate that Nanog interacted with a range of complexes of differing composition in ES cells. However, the SEC profile of purified rNanog (Fig. 1F) implies that the SEC profile of Nanog in ES cell lysates is not due solely to interaction of Nanog with other proteins; rather 
anomalous migration of Nanog in SEC is likely a consequence of a combination of Nanog dimerisation and the possession of a flexible non-globular conformation.

To further examine the hydrodynamic properties of Nanog, we expressed $\operatorname{Nanog}_{1-160}$ in E. coli in a soluble form. $\operatorname{Nanog}_{1-160}$ extends from the $\mathrm{N}$-terminus through the HD and binds DNA specifically according to EMSA (data not shown). SEC indicates that $\operatorname{Nanog}_{1-160}$ is monomeric with an apparent molecular weight close to its calculated weight $(20.5 \mathrm{kDa}$; Fig.1F). Thus the anomalous migration of Nanog on SEC is due to sequences C-terminal to residue 160.

\section{Mapping of the Nanog dimerisation domain}

To determine the location of the Nanog dimerisation domain, co-transfections were performed using two forms of Nanog tagged with different epitopes (Fig. 1A) in COS cells (Fig. 2) and ES cells (Supplementary Fig. 2). Co-immunoprecipitation of (HA) ${ }_{3} \mathrm{Nanog}$ with (Flag $)_{3} \mathrm{Nanog}$ indicated that this approach could detect Nanog dimerisation and that deletion of the N-terminal region or the HD, either individually (Fig. 2A; Supplementary Fig. 2A) or together (Fig. 2B) did not prevent co-immunoprecipitation. Thus residues 160-305 are sufficient to mediate Nanog dimerisation. Deletions from the C-terminus resulted in a failure to co-immunoprecipitate (Flag) ${ }_{3}$ Nanog upon deletion of the entire 146 residue C-terminal domain but not upon deletion of the C-terminal 20 or 49 residues (Fig. 2A; Supplementary Fig. 2A). This suggests that the dimerisation domain is located between residues 159 and 256. To further pinpoint the dimerisation domain, residues 188-248, encompassing the WR region, were deleted. The failure of (HA) ${ }_{3} \mathrm{Nanog} \Delta \mathrm{WR}$ to coimmunoprecipitate full length (Flag) ${ }_{3}$ Nanog (Fig. 2C; Supplementary Fig. 2B) establishes that WR is required for Nanog dimerisation. Moreover, the similarity in the results obtained in ES cells and COS cells indicates that ES cell-specific proteins do not provide additional bridging interactions between Nanog monomers independent of the WR.

Analysis by SEC of ES cell lysates expressing the $\triangle \mathrm{WR}$ mutant show that (HA) $)_{3} \operatorname{Nanog} \Delta \mathrm{WR}$ runs at a position substantially different from $(\mathrm{HA})_{3} \mathrm{Nanog}$ and more consistent with its calculated monomeric molecular weight (Fig. 1F).

\section{Dimerisation of Nanog is mediated directly through the tryptophan repeat}

To determine whether the WR region is sufficient to mediate direct dimerisation, rNanog was passed over an amylose column to which the fusion protein MBP-tryptophan repeat (MBP-WR) or MBP alone had previously been immobilized. Bound material eluted with maltose and analyzed by immunoblotting showed that rNanog bound specifically to immobilized MBP-WR (Fig. 2D). This indicates that the WR region mediates direct Nanog dimerisation.

\section{The tryptophan repeat is required to confer cytokine-independent self-renewal}

Finally, transfection of E14/T ES cells with episomal DNAs [2] was used to examine the effect of deletion of the dimerisation domain on Nanog function. Deletion of sequences C-terminal to the HD abolished cytokine-independent colony formation, whereas deletion of sequences C-terminal to the WR did not (Fig. 2E). Deletion of WR resulted in a failure to confer cytokine-independent colony formation (Fig. 2E). Similar results were obtained from transfection of $\mathrm{Lifr}^{-/-}$LRK1 ES cells eliminating any concern that the functionality of (HA) ${ }_{3} \mathrm{Nanog} \Delta \mathrm{C} 49$ could be due to an indirect effect upon LIF signalling in the E14/T cells (Supplementary Fig. 3). Comparative immunoblotting and immunofluorescence indicated that functional impairment of (HA) $)_{3} \mathrm{Nanog} \Delta \mathrm{WR}$ was not due to reduced expression or mislocalisation (Supplementary Fig. 3). These results indicate that the dimerisation domain is required for the biological activity of Nanog.

\section{DISCUSSION}

ES cell self-renewal efficiency is proportional to the expression level of Nanog [2,7]. The discovery that Nanog WR is a dimerisation domain necessary for cytokine-independent ES cell selfrenewal is an important step towards understanding how Nanog works. Previous biochemical studies of Nanog function suggested that the sequence C-terminal to WR (CD2) and, to a lesser extent, WR itself could both act as transactivation domains [9]. Furthermore, recent analysis of ES cells carrying integrated Nanog transgenes has suggested a role for CD2 in ES cell self-renewal [15]. This contrasts with our episomal expression analysis, performed in two ES cell lines, in which deletion of the Cterminal 49 residues encompassing CD2 did not eliminate the ability of Nanog to confer cytokine- 
independent ES cell self-renewal. This apparent discrepancy is likely related to the higher expression level achieved by episomal versus integrative transgenic expression. Nevertheless, our results clearly indicate that it is the WR dimerisation domain rather than CD2 that has the major role in conferring cytokine-independent self-renewal, the defining biological activity of Nanog, upon transfected ES cells (Fig.2).

Most non-plant HD proteins that oligomerise form homodimers (or heterodimers with other HD proteins) through interactions involving their HDs [16]. Thus, their cognate DNA sequence normally consists of two regions, each recognized by the HD of a different subunit, separated by just a short linker. In contrast, Nanog dimerization is mediated not by HD but by the WR, which is separated from the HD by 42 residues. Thus, the cognate DNA sequence of Nanog may also consist of a pair of DNA recognition sites but these may be positioned further apart, especially if the WR-WR interaction were head-to-tail. Amongst the few non-plant HD proteins that dimerise using non-HD interactions are Hnfl $\alpha$ [17] and PRH/Hex [18]. However, the influence of dimerisation on target site selection in these cases is unknown.

Dimerisation is likely to affect the interaction of Nanog with identified Nanog protein binding partners $[10,13,14,19]$ because different binding surfaces will be available on monomers versus dimers. Therefore, Nanog may interact with some partner proteins only when dimeric. In this context, it is notable that the interaction of $\mathrm{HNfl} \alpha$ with the transcriptional coactivator $\mathrm{DCoH}$ requires contributions from both $\mathrm{HNf1} \alpha$ subunits [17]. It is also possible that interactions between Nanog and other binding partners is mediated through monomeric Nanog and that deleting the WR destroys the ability of Nanog to form homodimers or heterodimers. In either case, the observations that the Nanog $\Delta$ WR does not form a dimer and that it cannot confer cytokine-independent self-renewal suggests that dimerization is a key regulator of Nanog activity. In this regard the AUC-based evidence that Nanog exists in equilibrium between monomeric and dimeric forms in vitro suggests an intuitively attractive mechanism by which Nanog function could be modulated. Covalent modification of Nanog might alter the steady state of the monomer-dimer equilibrium and so promote or suppress self-renewal activity. Further studies will be required to determine whether Nanog phosphorylation [12], or some additional covalent modification, could play such a regulatory role.

\section{ACKNOWLEDGEMENTS}

We thank Dr. R. Poot (Rotterdam) for comments on the manuscript. This research was supported by the Biotechnology and Biological Sciences Research Council and the Medical Research Council of the UK and by the Wellcome Trust and Juvenile Diabetes Research Foundation.

\section{REFERENCES}

1 Smith, A. G. (2001) Embryo-derived stem cells: of mice and men. Ann. Rev. Cell. Dev. Biol. 17, 435-462

2 Chambers, I., Colby, D., Robertson, M., Nichols, J., Lee, S., Tweedie, S. and Smith, A. (2003) Functional expression cloning of Nanog, a pluripotency sustaining factor in embryonic stem cells. Cell 113, 643-655

3 Mitsui, K., Tokuzawa, Y., Itoh, H., Segawa, K., Murakami, M., Takahashi, K., Maruyama, M., Maeda, M. and Yamanaka, S. (2003) The homeoprotein Nanog is required for maintenance of pluripotency in mouse epiblast and ES cells. Cell 113, 631-642

4 Ivanova, N., Dobrin, R., Lu, R., Kotenko, I., Levorse, J., DeCoste, C., Schafer, X., Lun, Y. and Lemischka, I. R. (2006) Dissecting self-renewal in stem cells with RNA interference. Nature 442, 533-538

5 Hough, S. R., Clements, I., Welch, P. J. and Wiederholt, K. A. (2006) Differentiation of mouse embryonic stem cells after RNA interference-mediated silencing of OCT4 and Nanog. Stem Cells 24, 1467-1475

Hatano, S. Y., Tada, M., Kimura, H., Yamaguchi, S., Kono, T., Nakano, T., Suemori, H., Nakatsuji, N. and Tada, T. (2005) Pluripotential competence of cells associated with Nanog activity. Mech. Dev. 122, 67-79 
Chambers, I., Silva, J., Colby, D., Nichols, J., Nijmeijer, B., Robertson, M., Vrana, J., Jones, K., Grotewold, L. and Smith, A. (2007) Nanog safeguards pluripotency and mediates germline development. Nature 450, 1230-1234

8 Jauch, R., Ng, C. K., Saikatendu, K. S., Stevens, R. C. and Kolatkar, P. R. (2007) Crystal Structure and DNA Binding of the Homeodomain of the Stem Cell Transcription Factor Nanog. J. Mol. Biol. 376, 758-770.

9 Pan, G. and Pei, D. (2005) The stem cell pluripotency factor NANOG activates transcription with two unusually potent subdomains at its C terminus. J. Biol. Chem. 280, 1401-1407

10 Wu, Q., Chen, X., Zhang, J., Loh, Y. H., Low, T. Y., Zhang, W., Zhang, W., Sze, S. K., Lim, B. and Ng, H. H. (2006) Sall4 interacts with Nanog and co-occupies Nanog genomic sites in embryonic stem cells. J. Biol. Chem. 281, 24090-24094

11 Robertson, M., Stenhouse, F., Colby, D., Marland, J. R., Nichols, J., Tweedie, S. and Chambers, I. (2006) Nanog retrotransposed genes with functionally conserved open reading frames. Mamm. Genome 17, 732-743

12 Yates, A. and Chambers, I. (2005) The homeodomain protein Nanog and pluripotency in mouse embryonic stem cells. Biochem. Soc. Trans. 33, 1518-1521

13 Suzuki, A., Raya, A., Kawakami, Y., Morita, M., Matsui, T., Nakashima, K., Gage, F. H., Rodriguez-Esteban, C. and Izpisua Belmonte, J. C. (2006) Nanog binds to Smad1 and blocks bone morphogenetic protein-induced differentiation of embryonic stem cells. Proc. Natl. Acad. Sci. U.S.A. 103, 10294-10299

14 Wang, J., Rao, S., Chu, J., Shen, X., Levasseur, D. N., Theunissen, T. W. and Orkin, S. H. (2006) A protein interaction network for pluripotency of embryonic stem cells. Nature $\mathbf{4 4 4}$, 364-368

15 Wang, Z., Ma, T., Chi, X. and Pei, D. (2007) Aromatic residues in the C-terminal domain 2 is required for Nanog to mediate LIF-independent self renewal of mouse embryonic stem cells. J. Biol. Chem. (2007) doi/10.1074/jbc.M706009200

16 Kasahara, H., Usheva, A., Ueyama, T., Aoki, H., Horikoshi, N. and Izumo, S. (2001) Characterization of homo- and heterodimerization of cardiac $\mathrm{Csx} / \mathrm{Nkx} 2.5$ homeoprotein. J. Biol. Chem. 276, 4570-4580

17 Rose, R. B., Endrizzi, J. A., Cronk, J. D., Holton, J. and Alber, T. (2000) High-resolution structure of the HNF-1alpha dimerization domain. Biochemistry 39, 15062-15070

18 Soufi, A., Smith, C., Clarke, A. R., Gaston, K. and Jayaraman, P. S. (2006) Oligomerisation of the developmental regulator proline rich homeodomain ( $\mathrm{PRH} / \mathrm{Hex}$ ) is mediated by a novel proline-rich dimerisation domain. J. Mol. Biol. 358, 943-962

19 Zhang, L., Rayner, S., Katoku-Kikyo, N., Romanova, L. and Kikyo, N. (2007) Successful coimmunoprecipitation of Oct4 and Nanog using cross-linking. Biochem. Biophys. Res. Commun. 361, 611-614 


\section{FIGURE LEGENDS}

Figure 1. Hydrodynamic properties of Nanog. A. Representation of expressed constructs. Full length Nanog protein is shown divided into the regions delimited by the residues indicated at the top and defined in the boxes; $\mathrm{ND}=\mathrm{N}$-terminal domain; $\mathrm{HD}=$ homeodomain; $\mathrm{CD} 1=\mathrm{C}$-terminal domain 1 ; $\mathrm{WR}=$ tryptophan repeat region; $\mathrm{CD} 2=\mathrm{C}$-terminal domain 2 ; His $=(\mathrm{His})_{6}$ tag. B. Coomassiestained SDS-PAGE of purified, recombinant Nanog with the position of migration of $\mathrm{Mr}$ markers indicated (kDa). C-E Analytical ultracentrifugation of rNanog. rNanog was analysed by sedimentation equilibrium and the INVEQ plots and fits are presented C. rNanog + NP-40 D. rNanog + NP-40 in $\mathrm{H}_{2} \mathrm{O}^{18}$ E. rNanog in the absence of detergent. F. SEC-based analysis of rNanog, ES cell

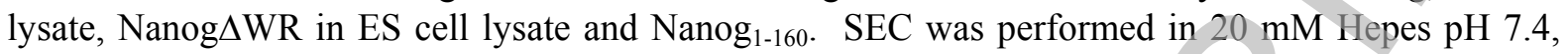
$200 \mathrm{mM} \mathrm{NaCl}$ on a $24-\mathrm{ml}$ Superdex 200 column run at $0.1 \mathrm{ml} / \mathrm{min}$ and fractions analyzed by Western blotting. Elution positions of molecular weight standards ( $\beta$-amylase, alcohol dehydrogenase, carbonic anhydrase and cytochrome $\mathrm{C}$ ) are marked (in $\mathrm{kDa}$ ). The position of the void volume (approx. 2 megadaltons) is marked (Vo).

Figure 2. The tryptophan repeat is involved in Nanog-Nanog interactions. A, B and C. Epitope tagging studies. Co-transfections of (Flag) ${ }_{3} \mathrm{Nanog}$ and (HA) ${ }_{3} \mathrm{Nanog}$ deletion mutants into COS cells were performed as indicated. Immune complexes ( $\alpha$-Flag) were collected and immunoblotted with the indicated antibodies. (HA) ${ }_{3} \operatorname{NanogC}$ migrates ahead of the Ig light chains as indicated by the arrow in B. D. rNanog interacts with MBP-WR repeat fusion. rNanog was incubated with immobilized MBPWR or MBP. After extensive washing, bound protein was eluted and fractions analysed by SDSPAGE (upper panel is a Coomassie-stained gel) and immunoblotting with $\alpha$-Nanog antibody (lower panel). Lanes 1-4 are fractions from the MBP column, lanes 5-8 are from the MBP-WR column. $\mathbf{E}$. ES cell colony forming assays. E14/T cells were transfected with pPyPCAG carrying no insert (-), $(\mathrm{HA})_{3} \mathrm{Nanog}(\mathrm{wt})$ or $(\mathrm{HA})_{3} \mathrm{Nanog}$ derivatives with the indicated deletions. Cells were grown for twelve days in the absence of LIF, stained for alkaline phosphatase activity and the number of undifferentiated ES cell colonies counted; error bars are standard deviations $(n=3)$. 
B Biochemical Journal Immediate Publication. Published on 19 Feb 2008 as manuscript BJ20080134

A

Nanog

Nanog

(Flag) ${ }_{3}$ Nanog

(HA) ${ }_{3}$ Nanog

(HA) $\operatorname{Nanog} \Delta \mathrm{N}$

(HA) Nanog $\triangle H D$

(HA) ${ }_{3}$ anog $\triangle \mathrm{C}$

(HA) ${ }_{3}$ Nanog $\triangle W R$
(HA) ${ }_{3}$ Nanog $\Delta C 49$

$(\mathrm{HA})_{3} \mathrm{Nanog} \Delta \mathrm{C} 4$
$(\mathrm{HA})_{3} \operatorname{Nanog} \mathrm{C}$

MBP-WR

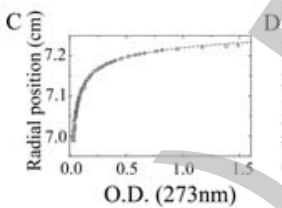

F ง

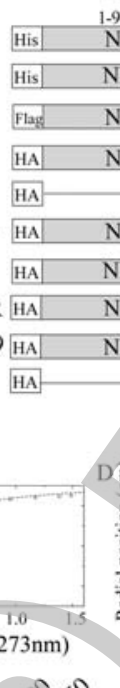

Mullin Figure 1

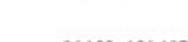

96-155 $156-19$
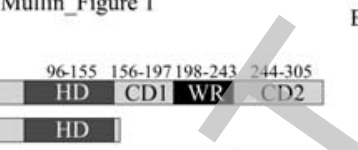

HD $\mathrm{C}$

CD1 WR CD2

\begin{tabular}{l|l|l|l|}
$\mathrm{HD}$ & $\mathrm{CD} 1$ & $\mathrm{WR}$ & $\mathrm{CD} 2$ \\
\hline
\end{tabular}

HD CD1 WR CD2

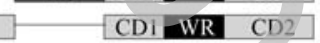

MID

\begin{tabular}{ll|l|l|} 
& $\mathrm{HD}$ & $\mathrm{CD} 1$ & $\mathrm{CD} 2$ \\
\hline
\end{tabular}

ND I HD CDI WR

\begin{tabular}{|lll}
\hline CD1 WR & CD2 \\
\hline
\end{tabular}

MBP WR His
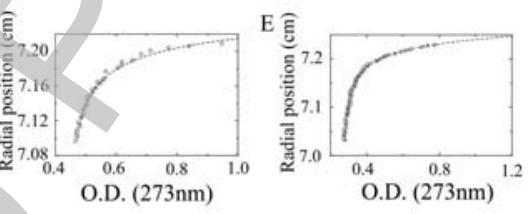

$?^{2}$

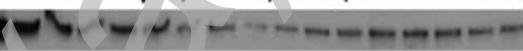

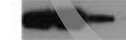

$-\cdots$$$
-\infty
$$

ES cell lysate

\section{rNanog}

$\triangle W R$ ES cell lysate

Nanog 1-160

B

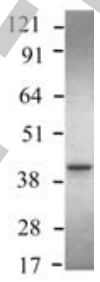

91 -

51 -

38 -

28 -

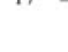

sers

.




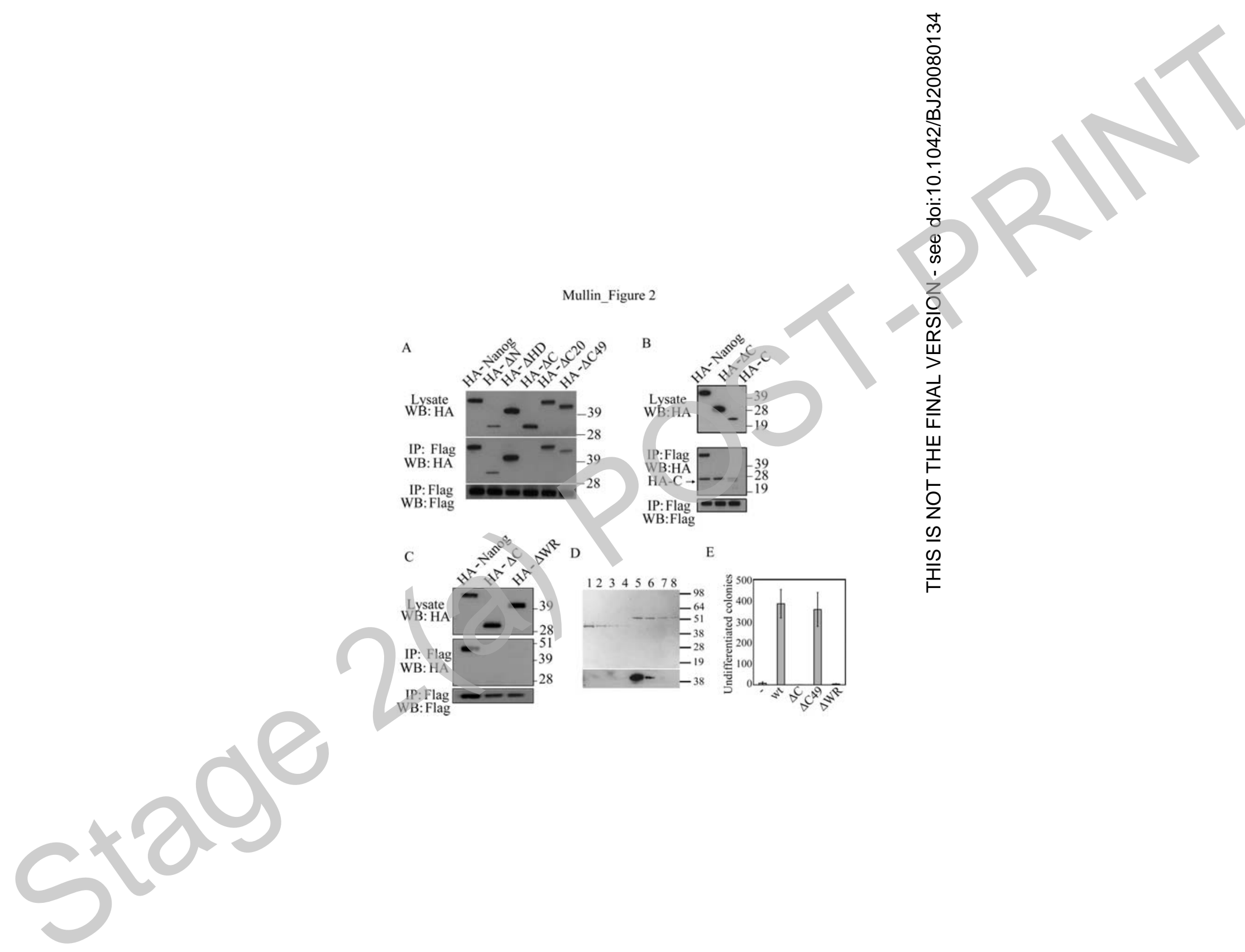

Licenced copy. Copying is not permitted, except with prior permission and as allowed by law. (c) 2008 The Authors Journal compilation (c) 2008 Biochemical Society 